\title{
The Impact of Using an Infographic-based Training Program on Improving Visual Motor Memory Among EFL Students
}

\section{Mohammad Abedrabbu Alkhawaldeh* and Mohamad Ahmad Saleem Khasawneh}

Special Education Department, King Khalid University, Saudi Arabia

\section{Article Type: Article \\ Article Citation: Mohammad Abedrabbu Alkhawaldeh, Mohamad Ahmad Saleem Khasawneh. The impact of using an infographic-based training program on improving visual motor memory among EFL students. Indian Journal of Science and Technology. 2020; 13 (04), 405-416. D0l: 10.17485/ ijst/2020/v013i01/148906}

Received date: November 14, 2019 Accepted date: December 13, 2019

*Author for correspondence: Mohammad Abedrabbu Alkhawaldeh Vmalkhawaldeh@kku.edu.sa 9 Special Education Department, King Khalid University, Saudi Arabia

\begin{abstract}
Objectives: This study aimed at investigating the impact of an infographic-based training program on improving the visual motor memory among EFL students. Methods/statistical analysis: The study used a semi-experimental approach and the program was applied on $60 \mathrm{EFL}$ students enrolled in the schools of the Directorate of Education in Asir region, Saudi Arabia. The students were divided into two groups: an experimental and control groups. The researcher applied the training program on students after training the teachers on how to better utilize all the elements of the training program effectively. Findings: The results showed statistically significant differences in the post-test of visual motor memory skills between the experimental and control groups, which were in favor of the experimental group. The results also revealed that there were no statistically significant differences in the visual motor memory posttest due to the variables of gender and interaction between group and gender. The study concluded that using infographics enhanced the participants' visual motor memory skills in learning English as a second language regardless of their gender, which indicates the appropriateness of the training program for such students. Application/improvements: The study recommended this training program to be used by EFL teachers and EFL curricula designers to consider integrating infographics in the design of these courses.
\end{abstract}

Keywords: Infographics, Vlsual Motor Memory, EFL students.

\section{Introduction}

Piaget points out that the mental construction of the child is gradually formed at the end of the kinetic stage and at the emergence of symbolic functions. This construction is supported in the pre-conceptual phase at the age of 2-4 years and becomes more mature at the concrete operational phase at the age of 4-7. As such, the child starts to notice different 
things and distinguish between their similarities and differences. The child becomes able to distinguish between the negative and positive examples of the concept and performs the process of classification. Therefore, visual learning for students in advanced curricula is like basic threads in the holistic construction of the curriculum, where students learn through variable and comprehensive experiences that enrich the curriculum, attract the child, and draw his/her interest. Examples of these experiences are participating in scientific experiments and educational stories by engaging students in the active acting, connecting between things and events effectively and employing the learning process to raise their natural curiosity to recognize the surrounding environment [1-2].

Everything that draws the attention could be learned, and that the lack of attention leads students to have weak academic achievement, where their concentration to the basic elements of the visual catalyst is weak. Therefore, they need someone or something to attract their attention to these important elements, which, in this study, is the role of infographic learning and its different kinds to concentrate the attention of EFL students in an exciting multimedia learning environment that addresses more than one of their senses. This is reflected in improving their academic achievement and learning competency. $\mathrm{He}$ also stressed that when the teacher addresses more than one sense in the learner, the learning process is more likely to occur.

\subsection{Statement of the Problem}

Infographic learning is a major factor in helping students from different perspectives. Studies have proved that students with low achievement live in a high risk of social isolation, loneliness, and low social support [3]. Using infographic techniques in teaching increases the social interaction, building relationships with others, and reduces the feeling of loneliness [4]. Infographic learning plays a vital role in increasing motivation, participation, and self-esteem among students [5]. Previous studies [6] revealed that learners could obtain information more clearly and effectively through pictures, illustrations, graphs, electronic charts better than information that depend on pronunciation. It is more difficult for the learner to retrieve what has been learned from mere pronunciation of information. Therefore, there is a need for reading skills and the ability to design pictures and electronic illustrations for the learner.

Most studies that tackle using infographic learning are focused on regular students and students with some types of disabilities. However, to the best knowledge of the researcher, studies that addressed the use of infographic in learning and teaching are still rare.

\subsection{Research Objectives}

This study aims at achieving the following objectives:

a- To determine the impact of using infographic-based training program on improving visual motor memory skills in English among EFL students in Asir region.

b- To identify the techniques and teaching methods of infographics in teaching English as a foreign language among EFL students in Asir region.

c- To provide recommendations for curricula designers on these techniques. 


\subsection{Research Questions}

This study attempts to answer the following questions:

a- Do students who receive infographic-based training program perform better on visual motor memory skills in English than those who received conventional based training?

b- Do students who receive infographic-based training program perform better scores on pretest on visual motor memory skills in English than those who received conventional based training?

c- Do students who receive infographic-based training program perform better scores on posttest on visual motor memory skills in English than those who received conventional based training?

\subsection{Hypotheses of the Study}

Hal: students who receive infographic-based training program perform better on visual motor memory skills in English than those who received conventional based training.

Ha2: students who receive infographic-based training program perform better scores on pretest on visual motor memory skills in English than those who received conventional based training.

Ha3: students who receive infographic-based training program perform better scores on posttest on visual motor memory skills in English than those who received conventional based training.

\subsection{Significance of the Study}

The significance of this study stems from being an interesting teaching method that helps students to learn easily. The study can also assist teachers in using infographic techniques in education, which will allow them to interact with this category of students and achieve learning objectives and efficiency. Using infographics in teaching EFL students may increase their willingness and motivation to learn and understand new concepts and information in an interesting and exciting way. Moreover, this technique may attract the attention of curricula designers, whether the conventional or the electronic, to the importance of adding infographic designs to curricula to facilitate the education process.

\subsection{Limitations of the Study}

The results of this study are strongly tied to the EFL teachers, who will implement this teaching program and who work in the schools in Asir's Educational Directorate during the first semester of the school year 2018-2019. The results are also limited to performing the validity and reliability of the study tools correctly, the extent that the sample of the study represent the study population, and the seriousness of the participants in the training program 


\section{Literature Review}

\subsection{Infographic Technology}

Infographic technology and its various designs have emerged in an attempt to provide a new visual form for collecting and presenting information and data transmission in an attractive way for learners. Infographic designs are very important because they change the way of thinking about complex data and information and assist curricula designers to provide engaging materials. Infographic is a concept that refers to transforming information and data into illustrations that are easy to comprehend by the viewer without reading many texts [7]. It is one of the most effective methods nowadays and the most attractive to display information because of its simplicity, speed, and entertainment in presenting information to the recipient. Using such technology simplifies complex and large information and makes them more comprehensive through using visual effects in sending and transferring boring numbers and letters to more interesting images and illustrations that are easy to be published on electronic devices. Infographics rely on using numbers, words, symbols, colors, and pictures to send the key message to the reader [8].

The work of the visual memory, in the academic environment, is concentrated on pictures, symbols, numbers, letters, and words. When it comes to words, students must be able to look at the shape of the word in their minds to be able to retrieve it back later. Therefore, when the teacher introduces a new word, he/she writes on the board and asks students to look at it, spell it, read it, use it in a sentence, and then the teacher the erase the word from the board. Students with good visual memory recognize the same word whenever mentioned in the text because of their ability to retrieve the word [9]. Therefore, this study builds a mixed teaching method of infographics and visual memory through designing an infographic-technique training program to improve the visual motor memory among EFL students.

\subsection{Visual Motor Memory}

Visual Motor Memory (VMM) is the integration of both eyes and hands to work together efficiently and in specific patterns and includes visual perception the coordination between visual and touch senses. Visual Motor memory depends on acquiring the skill of transforming this visual perception into motor functioning and motor control, motor accuracy, and psychomotor speed [10]. Many techniques can be used to develop this skill among students and among these methods the use of infographics in teaching visual communication skills and in designing the visual message that reflects the ability to read, explain, and understand advanced information in pictures and graphs. It is related to visual thinking, which is defined as the ability to convert the different kinds of information to pictures or illustrations that help in communicating this information. Therefore, the educational-technological relationship between infographics and visual memory plays an important role in providing lessons for the learner and helping students to gain high skills in receiving information using a new interesting method. 


\subsection{Previous Studies Related to Infographic and Visual Motor Memory}

One study conducted in Saudi Arabia aimed at exploring the impact of using a mobile learning environment based on the use of interactive infographic and at measuring its impact in developing the audio-listening comprehension skills of the English students at Umm Al-Qurra University. The study used the descriptive and quasi-experimental designs. The sample of the study consisted of 76 students, who were chosen randomly and divided into two groups, an experimental group and a control group. The results of the study showed that the experimental group achieved better scores in the post-test at the levels of analysis, synthesis, evaluation, the achievement test, as well as in the listening comprehension skills [11].

Another study conducted in Cyprus aimed at developing an instructional design based on the ADDIE (Analysis, Design, Development, Implementation, Evaluation) model of infographic design to teach elementary school students. The sample of the study consisted of 43 teachers and 51 students from elementary schools in Cyprus. The study followed the experimental approach, where 52 hours of education in face-to-face and online learning environments with the sample were conducted. In order to collect data of this study, the researchers developed a "self-efficacy scale for the design and usage of infographics," the "opinion survey for the usage of infographics in teaching environments," a "semi-structured interview form for the design of infographics for teachers and their usage in teaching environments", and a "semi-structured interview form for elementary school students for the usage of infographics in education." The results of the study showed significant differences in the perspectives of participants, both teachers and students, toward using infographics in the learning environments [12].

In Saudi Arabia, one study conducted to investigate the effect of using infographics on university female students' achievement and to explore the students' perceptions of the infographics' impact. The study was a quasi-experimental design, and the sample consisted of 165 participants divided into two groups: experimental $(\mathrm{N}=83)$ and control $(\mathrm{N}=82)$. The intervention was implemented for a period of 9 sessions each of 2 hours duration. In order to collect data, the researcher used achievement tests and a questionnaire to measure students' perceptions. The results of the study showed that the experimental group showed higher academic achievement than in the control group.

The results also revealed that $90 \%$ of the participants expressed their satisfaction toward infographics and its positive impact on their intellectual, life skills, and effective development [13].

Another study conducted also in Cyprus showed students' satisfaction about using infographics and indicated that the educational environment is of a rich nature and using this technique led to acquiring learning skills, motivation, and innovation. Therefore, students favored to be taught by visual materials rather than books or traditional tools [14].

Another study conducted in Saudi Arabia to identify the impact using infographics in the teaching of linguistics for female Saudi EFL students. The study investigated the perceptions of female students toward using this technique and explored the advantages 
and disadvantages of such usage. The sample of the study was formed of 186 Saudi female college students from the Department of Translation at the College of Languages in Princess Nourah bint Abdulrahman University (PNU). The study used the descriptive and quasi-experimental design, where the sample answered a 26-item questionnaire. After the analysis of data, the results showed that students had positive attitudes toward using infographics in linguistic courses and toward improving the existing skills they had, such as critical thinking [15].

Finally, one study conducted in in the Saudi context to identify the effect of using infographic techniques on academic achievements of eighth grade students in math. The study used the experimental approach, and the sample of the study consisted of 63 students, where the experimental group was 30 students, who were taught using the infographic technique, and the control group was 33 students, who were taught using conventional methods. Both groups were subject to post-test. The results of the study revealed the existence of statistical significant differences between the mean scores of the experimental group. The result showed the importance of using infographic technique to teach math and recommended that further research to be conducted on other subjects [16].

Most of the previous studies focused on the importance of infographics in the education process in teaching different subjects in different environments. Some of the previous studies tackled using infographics in teaching EFL students by focusing on teaching some skills, such as grammar and listening. This study is different in its approach of tackling the issue of using infographics in teaching EFL students, which is done by designing a special infographic-based training program to improve the visual motor memory skills among EFL students in Saudi Arabia. The study attempts to focus on improving visual motor memory skills as an important aspect of acquiring a second language.

\section{Research Methodology}

This section provides information on the methodology of the present study, which includes population and sample, research instrument, and validity and reliability of the instrument.

\subsection{Research Design}

This study was based on the experimental approach by utilizing the quasi-experimental methodology. The rationale behind using this approach is because of its suitability to the nature of the study and its objectives. Therefore, the researcher divided participants into two groups, an experimental group and a control group, in order to achieve the study objectives. The same teacher, who was instructed by the researcher on the techniques to teach the program, taught both groups, the experimental and control.

\subsection{Sample of the Study}

The population of the study consisted of all 326 EFL students enrolled at schools of the Educational Directorate of Asir, Saudi Arabia, whose ages were between 8 and 12 years 
old and who study in third, fourth, fifth, and sixth grades. The sample of the study was 60 students, $(\mathrm{n}=30)$ males and $(\mathrm{n}=30)$ females, who were chosen using the simple random method. The sample was divided into an experimental group and control group. Table 1 presents the distribution of the study sample according to the study variables.

\subsection{Research Instruments of the Study}

\subsubsection{Visual Motor Memory Skills Test}

This test is non-verbal and is used to measure the ability of students to reproduce symbolic forms from the short-term memory. The test includes features such as the recollection of visual symbols from the memory, the ability to perform visual sequencing, visual deterioration skills, visual motor ability, ability of visual integration, and skills related to symbolic integration.

The test consists of 10 letters, each one is placed inside a square and under each square, and a corresponding symbol is added. The student has to link between the picture and the first letter inside the square.

\subsubsection{Validity and Reliability}

The test validity is to investigate whether the test is measuring the desired objectives and not something else [17]. The validity of the test was achieved by presenting the test to 10 referees working in education in order to review the scale and provide feedback. Their opinions and suggestions were taken into consideration. Some items and paragraphs were amended until all referees agreed on the used vocabulary and content. One item was deleted and two were added based on the request of referees.

The reliability of the scale was achieved by using test-retest method through applying a pilot study on 20 students. The Pearson correlation coefficient was calculated for the scores on the two tests. The Spearman correlation coefficient was calculated by retest of the scale, which was ${ }^{* *} 0.825$. The stability coefficient was calculated using the Cronbach's alpha formula. The stability coefficient of the internal consistency of the scale as a whole was 0.896 , indicating that the scale has an appropriate level of stability.

\subsubsection{The Infographic-based Braining Program}

This study is based on applying an infographic-based program to improve visual motor memory skills in English among EFL students in Asir region. The researchers designed

TABLE 1. Distribution of the study sample according to group, school, and gender

\begin{tabular}{lllc}
\hline Group & School & Gender & Total \\
\hline \multirow{2}{*}{ Experimental } & Habib Bin Zaid Elementary school & Males & 15 \\
& First Elementary School & Females & 15 \\
\multirow{2}{*}{ Control } & Al-Zahra Elementary School & Males & 15 \\
& Nineteenth Elementary School & Females & 15 \\
\hline
\end{tabular}


the training program to improve visual motor memory skills through different steps. The researchers first reviewed the literature and previous studies related to the subject of the study and identifying the training needs of EFL students. The researchers presented the program to 10 specialized judges from King Khalid University and the Ministry of Education. The purpose of this step was to identify the appropriateness of the training program to the Saudi context, the clarity of its linguistic drafting, and the appropriateness of strategies and methods used in improving the visual motor memory among EFL students. Based on the judge's reviews, some paragraphs have been deleted, added, or amended in order to reach the final form that fits the specified objectives. The methods included in this program vary from direct instructions, providing feedback from teachers, performing behavior rehearsal by students and the assistance of teachers, and the reinforcement using material and moral techniques.

\subsubsection{Content Validity of the Training Program}

The program was presented to a group of referees in order to identify the relevance of the objectives to the content of the program, the suitability of the educational procedures used, and linguistic drafting for the target age group of EFL students. The training program has been changed based on their opinions. The percentage of agreement among the referees was $86 \%$, which is an important indicator of the validity of the content and is acceptable for the purposes of study.

\subsection{Research Procedures}

\subsubsection{Design and Content of the Program}

Because of the lack of existing content that aims to treat the improvement of visual motor memory among EFL students, the researcher developed the content from previous literature. The researchers put into consideration while developing the content of the program different issues, such as that the treatment to be diverse, the activities of the training program to be focused on visual motor memory processes, the training program to depend on interaction and engagement between the teacher and the student individually or in small groups, and finally, the program to consider the levels of EFL students and paying attention to presenting the different stimuli using infographic techniques. The content of the program included a pre-test which aims at identifying the initial levels of the sample of the study by applying the visual motor memory test prepared by the researcher for the purposes of this study, and which was conducted before implementing the program. The program also contained formative assessment that aims at identifying the levels of the sample during the implementation of the training program. It also aims to recognize the extent of achieving the behavioral objectives of the program. Formative assessment was conducted after each activity and after each stage of the training program. Teachers used questions and observation in this kind of assessment.

Finally, the post-test of this program aimed at identifying the effectiveness of the proposed training program through applying the visual motor memory post-test prepared by the researcher after the sessions of the training program. 


\subsubsection{Implementation of the Training Program}

The researcher trained the teachers on the teaching using the infographic technique, where he held four consecutive sessions to present the technique of the infographic to teachers; these sessions lasted four and a half hours each over a period of 3 days. The researcher then carried out two classes using the infographics with the presence of teachers in order to clarify the method of implementation and to answer teachers' questions. Teachers then conducted two classes using the infographics with the presence of the researcher. Both the teachers and the researcher discussed the methods of implementation and identified positive and negative aspects in order to improve performance. The researcher attended two weekly classes with each teacher while teaching using infographics to ensure proper implementation and to discuss new updates.

\subsection{Data Analysis}

The returned test was recorded and tabulated with the assistance of Statistical Package for Social Sciences (SPSS) for windows 17.0 to identify the correlated relationships of variables concerning using infographic technology in enhancing visual motor memory among EFL students. Different statistical methods were used to achieve the main objectives of the present investigation. These methods included descriptive statistics, independent sample T-Test, and analysis of variance (ANOVA). Descriptive statistics, including means, standard deviation and frequencies, which were computed to summarize the EFL students' responses to infographic technology. Moreover, descriptive statistics and frequencies were employed to calculate the demographic data of the EFL students with regard to gender and interaction between groups and gender. An independent sample T-test is a statistical method employed to demonstrate the variations among the means of two groups of a variable. In the current research, this statistical method was used in order to identify the significant differences between EFL students using infographic technology and their gender. An analysis of variance (ANCOVA) is a method of statistical analysis used to determine differences among the means of more than two groups of a variable [18]. In the present study, this statistical method was used to identify the significance of these differences and their level.

\section{Findings and Discussion}

This section presents the findings obtained from the present study, which are guided by the research questions.

In order to answer the first question of the study about the differences between the mean scores of the experimental and control group in thin the visual motor memory skills, the mean and standard deviations of both groups were calculated for the pre- and posttests (see Table 2).

Table 2 shows that the mean scores of the experimental group in the pre-test was 50.53 while in the post-test was 49.33 . On the other hand, the mean scores of the control group in the pre-test was 48.20 while in the post-test was 50.33 . In order to identify the statistical 
The Impact of Using an Infographic-based Training Program on Improving Visual Motor Memory Among EFL Students

TABLE 2. Mean scores and standard deviations of EFL students' scores in the pre- and post-tests of visual motor memory according to the variable of group

\begin{tabular}{lccccc}
\hline \multirow{2}{*}{ Group } & Number & \multicolumn{2}{c}{ Pre-test } & \multicolumn{2}{c}{ Post-test } \\
\cline { 3 - 6 } & & $\begin{array}{c}\text { Mean } \\
\text { score }\end{array}$ & $\begin{array}{c}\text { Standard } \\
\text { deviation }\end{array}$ & Mean score & $\begin{array}{c}\text { Standard } \\
\text { deviation }\end{array}$ \\
\hline Experimental & 30 & 50.53 & 5.184 & 49.33 & 8.121 \\
Control & 30 & 48.20 & 5.536 & 50.33 & 4.420 \\
\hline
\end{tabular}

differences between the mean scores of both groups, analysis of variance (ANCOVA) was conducted (see Table 3).

Table 3 shows statistically significant differences in the mean scores of the experimental and control groups, where the F value was 686.5. Therefore, the first null hypothesis and the alternative hypothesis is accepted; there are statistically significant differences at the level of $\alpha \leq 0.05$ in the visual motor memory test between the experimental group (which was taught using the infographic-based training program) and the control group (which was not taught using the proposed program).

These findings agree with the findings of previous studies, which concluded that the learner could obtain information more clearly and effectively by using pictures and illustrations drawn electronically better than information based on pronunciation. The improvement in the levels of visual motor memory skills among the experimental group could be attributed to the impact of the training program. The training tasks provided for students met their needs in remembering materials they face during the learning process, which helped in enhancing their visual motor skills. The members of the experimental group received all elements of the training program, such as instruction, feedback, behavioral practice, motivation, assignments, individual training, and group work, which all contributed to providing the opportunity to apply the training program effectively, and which eventually improved their visual motor memory skills.

In order to answer the second and third questions of the study related to the impact of gender and the interaction between gender and group, two hypotheses were tested by calculating the mean scores and standard deviations for each group: males and females, in the pre- and post-tests. The results are presented in Table 4:

Table 4 shows that the mean score of males of the experimental group in the post-test was 95.2, while the males of the control group scored 50.6. The mean score of females of the experimental group was 93.4 and the females of the control group scored 50. These

TABLE 3. Analysis of variance for the variable of group among EFL students in the visual motor memory test

\begin{tabular}{lccccc}
\hline Source & Sum of squares & Freedom & Mean square & F & Significance \\
\hline Pre-test & 279.352 & 1 & 279.3 & 7.238 & 009. \\
Group & 26496.2 & 1 & 26496.246 & 686.5 & 000. \\
Error & 2199.9 & 57 & 38.5 & - & - \\
Total & 31519.3 & 59 & - & - & - \\
\hline
\end{tabular}

*Statistically significance at $\alpha=0.05$. 
TABLE 4. Mean scores and standard deviations for males and females in pre- and post-tests

\begin{tabular}{lllccc}
\hline Group & Test & \multicolumn{3}{c}{ Gender } \\
\cline { 3 - 5 } & & Males & Females & Total \\
\hline Experimental & Pre-test & Mean score & 50.4 & 50.6 & 50.5 \\
& & St. deviation & 4.1 & 6.1 & 5.1 \\
& Post-test & Mean score & 95.2 & 93.4 & 94.3 \\
& & St. deviation & 7.64 & 8.74 & 8.12 \\
Control & Pre-test & Mean score & 48.2 & 48.1 & 48.2 \\
& & St. deviation & 4.87 & 6.30 & 5.53 \\
& Post-test & Mean score & 50.6 & 50 & 50.3 \\
& & St. deviation & 4.42 & 4.55 & 4.4 \\
\hline
\end{tabular}

findings could be attributed to the fact that the training program is not affected by the gender of the student, which means that the training program has the same impact on both genders among EFL students. Moreover, the age of the sample played an important role to show that differences in academic achievement appear less in this group, for differences start to appear after the age of 10 or 11.

\section{Conclusion and Recommendations}

This study aimed at identifying the impact of an infographic-based training program in improving visual motor memory among EFL students in Asir region, Saudi Arabia. The study attempted to find statistically significant differences in the scores of the experimental group, which received training in the program, and the control group, which was taught using conventional methods in terms of the variables of the study, gender and interaction between group and gender. The results of the study revealed that there is a clear difference between the scores of the sample of the study in the post-test of visual motor memory skills in favor of the experimental group due to applying the infographic-based training program. Using infographic technology in teaching EFL students have positive results in improving the students' visual motor memory skills.

Based on the results, the study recommends including infographic texts in elementary levels curricula. It is recommended that the Ministry of Education to conduct training workshops for teachers of EFL students to be trained to transform the scientific material into infographic texts to use in the classrooms. Infographic technique could be used along with other methodologies and teaching strategies in EFL classrooms. Moreover, it is recommended to include teachers' preparation programs to enable them to use infographic technology in planning, implementing, and evaluating lessons.

\section{Acknowledgment}

This study was sponsored by the Research Group Program of the Scientific Deanship at King Khalid University, Kingdom of Saudi Arabia (R.G.P.IL34L40). 


\section{References}

1. Natalija S. Infographics in education. Piktochart. 2013, 1-12.

2. Stetsenko A. Teaching-learning and development as activist projects of historical becoming: expanding Vygotsky's approach to pedagogy. Pedagogies: An International Journal. 2009; 5(1), 6-16.

3. Emerson E, McVilly K. Friendship activities of adults with intellectual disabilities in supported accommodation in Northern England. Journal of Applied Research in Intellectual Disabilities. 2004; 17(3), 191-197.

4. Caton S, Chapman M. The use of social media and people with intellectual disability: a systematic review and thematic analysis. Journal of Intellectual and Developmental Disability. 2016; 41(2), 125-139.

5. Davidson R. Using infographics in the science classroom. The Science Teacher. 2014; 81(3), 34.

6. Damyanov I, Tsankov N. The role of infographics for the development of skills for cognitive modeling in education. International Journal of Emerging Technologies in Learning (IJET). 2018; 13(1), 82-92.

7. Kibar PN, Akkoyunlu B. A new approach to equip students with visual literacy skills: use of infographics in education. In: European conference on information literacy. 2014, 456-465.

8. Niebaum K, Cunningham-Sabo L, Carroll J, Bellows L. Infographics: an innovative tool to capture consumers' attention. Journal of Extension. 2014; 53(6), 6.

9. Khasawneh MA, Al Ahmad FA, Al Khawaldeh MA. The effects of training program based on auditory perception skills in enhancing phonological awareness among learning disability students in Aseer region. Journal of Educational and Psychological Studies [JEPS]. 2018; 12(3), 591-604.

10. Sanghavi R, Kelkar R. Visual-motor integration and learning disabled children. The Indian Journal of Occupational Therapy. 2005; 37(2), 33-35.

11. Al-Samadani. HA, The effectiveness of using a mobile interactive learning environment based on interactive infographic in the development of listening comprehension skills of EFL students at Umm Al-Qura University. IUJ Journal for Educational and Psychology Sciences. 2019; 27(2), $1-16$.

12. Ozdamli F, Ozdal H. Developing an instructional design for the design of infographics and the evaluation of infographic usage in teaching based on teacher and student opinions. EURASIA Journal of Mathematics, Science and Technology Education. 2018; 14(4), 1197-1219.

13. Alrwele NS. Effects of Infographics on student achievement and students' perceptions of the impacts of infographics. Journal of Education and Human Development. 2017; 6(3), 104-117.

14. Bicen H, Beheshti M. The psychological impact of infographics in education. BRAIN. Broad Research in Artificial Intelligence and Neuroscience. 2017; 8(4), 99-108.

15. Dahmash AB, Al-Hamid A, Alrajhi M. Using infographics in the teaching of linguistics. Arab World English Journal (AWEJ). 2017; 8, 430-443.

16. Al-Duhaim L. The effect of the integration of Infographics in mathematics on the achievement of second-grade students. Mathematics Education Journal. 2016; 19(7), 263-281.

17. Thorndike RM, Cunningham GK, Thorndike RL, Hagen EP. Measurement and evaluation in psychology and education. Macmillan Publishing Co, Inc. 1991.

18. Basics of qualitative research. https://us.sagepub.com/en-us/nam/basics-of-qualitativeresearch/book235578. Date accessed: 2014. 